\title{
Omental torsion: a rare cause of acute abdomen
}

\section{Ketan Vagholkar*, Qurratulain Chougle, Purva Agrawal, Divya Daga, Suvarna Vagholkar}

D. Y. Patil University School of Medicine Navi Mumbai, Maharashtra, India

Received: 11 September 2016

Accepted: 15 September 2016

\section{*Correspondence:}

Dr. Ketan Vagholkar,

E-mail: kvagholkar@yahoo.com

Copyright: (C) the author(s), publisher and licensee Medip Academy. This is an open-access article distributed under the terms of the Creative Commons Attribution Non-Commercial License, which permits unrestricted non-commercial use, distribution, and reproduction in any medium, provided the original work is properly cited.

\section{ABSTRACT}

Torsion of the greater omentum is one of the rare causes of acute abdomen. However with an increase in the incidence of obesity in urban population there is a steady increase in the incidence of this rare and deceptive abdominal condition. The attending surgeon needs to be aware of this condition especially when confronted with an obese patient presenting as an acute abdomen. The paper reviews the etiopathogenesis and management of this rare condition.

Keywords: Omentum, Torsion, Diagnosis, Treatment

\section{INTRODUCTION}

Greater omentum is the greatest asset to the peritoneal cavity by virtue of its constabulary functions. However under rare circumstances it can be a cause for misdiagnosis and morbidity. Torsion of the omentum is an acute condition where in the greater omentum twists on its long axis to an extent which jeopardizes its vascularity. The condition was first described by Eitel in 1899. ${ }^{1}$ Subsequent to his description approximately 250 cases have been described in literature. ${ }^{2}$

\section{ETIOPATHOGENESIS}

The condition is predominantly seen in males, especially in obese males. Right side of the omentum is more affected due to greater mobility as compared to the left side. ${ }^{2,3}$ Torsion can be of two types. Primary Torsion where there is no associated pathology. However various anatomical factors have been described which pre dispose to primary torsion. ${ }^{2}$ These include accessory omentum, bifid omentum, irregular accumulation of omental fat in obese individuals, narrowed omental pedicle and occasionally redundancy of omental veins leading to kinking and twisting around the shorter and tense arteries.
Secondary torsion is more commonly associated with pre-existing pathologies. ${ }^{3}$ These include cysts, tumors, foci of intraabdominal inflammation and post-surgical scarring at hernia sites. Secondary torsion is commonly associated with inguinal hernias. This is due to the dependent omentum being fixed in a twisted position and thereby unable to untwist.

Certain precipitating factors have been described. These include trauma to the abdomen, violent exercise and hyper peristalsis associated with increased passive movement of the omentum. ${ }^{2-4}$

\section{NATURAL HISTORY}

Omentum usually twists in a clockwise direction (Figure 1). Venous return is impeded leading to severe congestion of the distal vessels. This causes severe edema and hemorrhagic extravasation. Hemorrhagic extravasation leads to accumulation of hemorrhagic serosanguinous fluid. The edema worsens leading to arterial compromise. ${ }^{3}$ The final outcome is hemorrhagic infarction (Figure 2). 


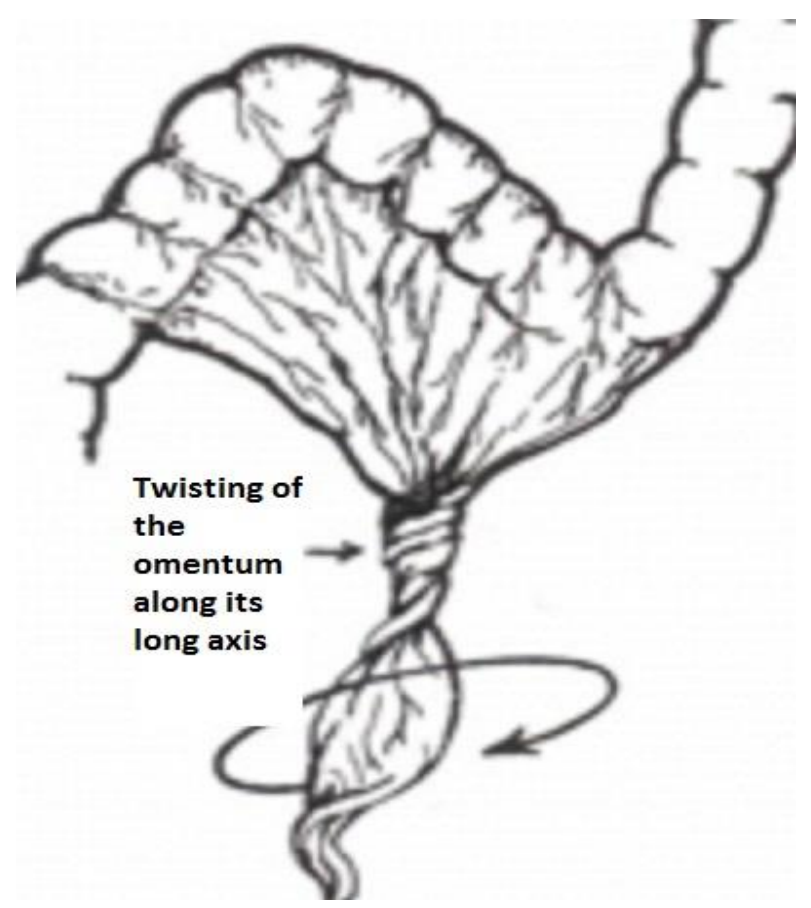

Figure 1: Rotation of the greater omentum along the long axis.

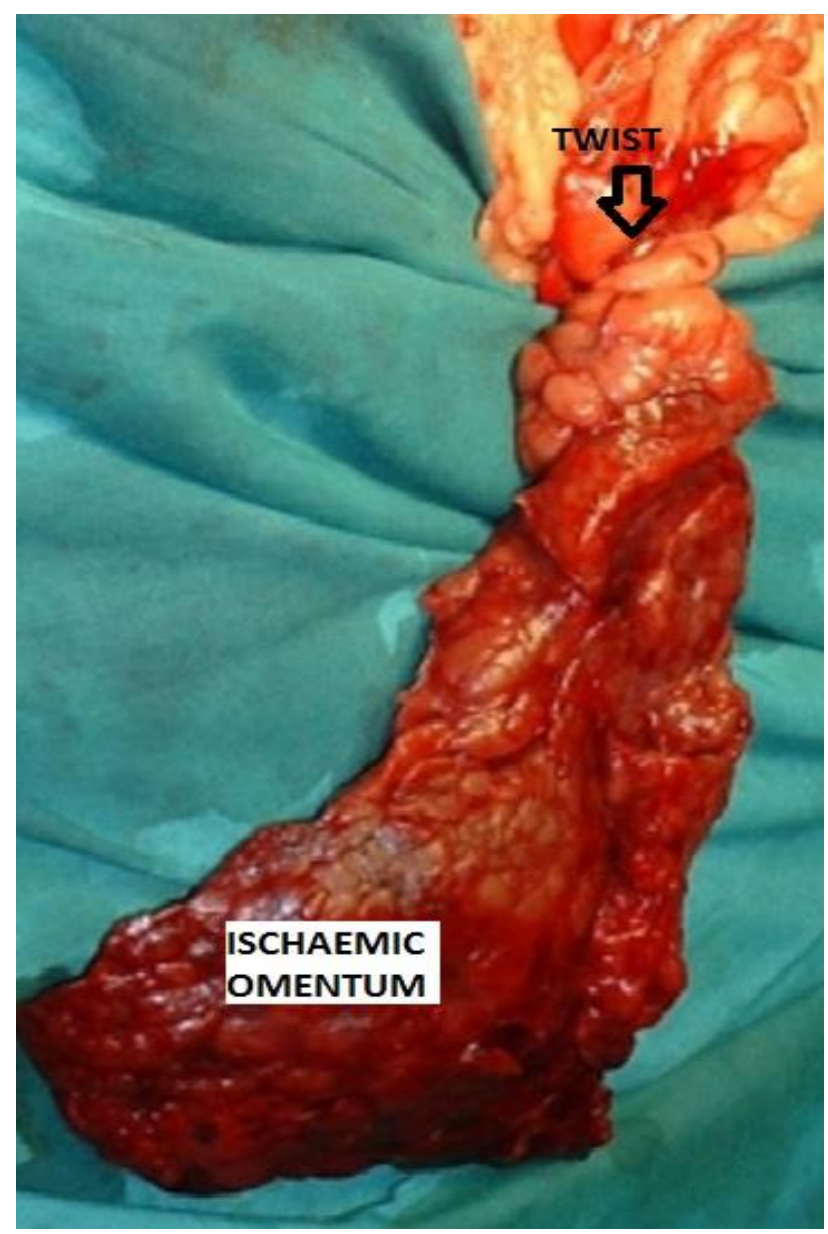

Figure 2: Hemorrhagic infarction of the greater omentum distal to the twist.

\section{CLINICAL FEATURES}

The patient usually presents with sudden onset of severe right sided lower abdominal pain. There is no history of radiation of pain. Vomiting may be an accompaniment of this condition. Physical examination will reveal signs of peritoneal irritation. In a few cases spontaneous resolution of symptoms may be seen. Such patients may subsequently experience intermittent lower abdominal pain due the development of omental adhesions.

\section{DIFFERENTIAL DIAGNOSIS}

In adults, omental torsion closely mimics acute appendicitis, cholecystitis, caecal diverticulitis or even a perforated peptic ulcer. In female patients it closely mimics right sided salpingitis, torsion of an ovarian cyst and in rare circumstances even a right sided ectopic pregnancy. In children, Meckel's diverticulum and acute mesenteric adenitis may closely mimic omental torsion.

\section{INVESTIGATIONS}

Hematological investigations may not reveal any diagnostic features. Ultrasound can be of great help in providing a lead to the diagnosis. It will typically show a hyper echoic, non-compressible, intra-abdominal mass usually adherent to the anterior abdominal wall located in the umbilical region or adherent anterolaterally to the right half of the colon (Figure 3). The main role of USG besides giving a clue to the diagnosis is to rule out other morbid causes of acute abdomen such as appendicitis, cholecystitis or acute adnexal lesions. ${ }^{4}$ Contrast enhanced CT scan (CECT) is diagnostic. It typically shows diffuse streaking in a whirl like pattern of fibrous and fatty folds (Figure 4). CECT has more sensitivity and specificity then USG. The mass is characteristically located between the anterior abdominal wall and the colon, best documented by CECT. ${ }^{5}$

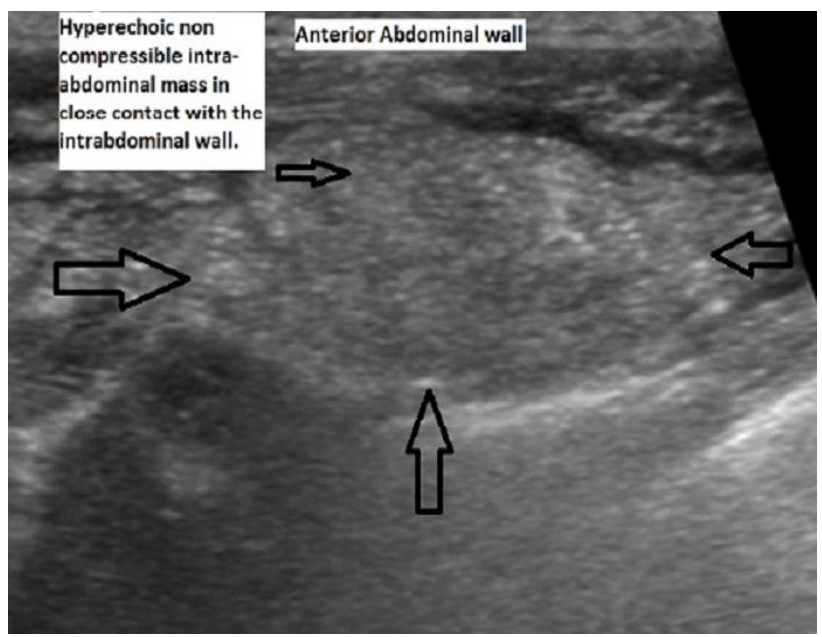

Figure 3: Ultrasound appearance in torsion of the omentum. 


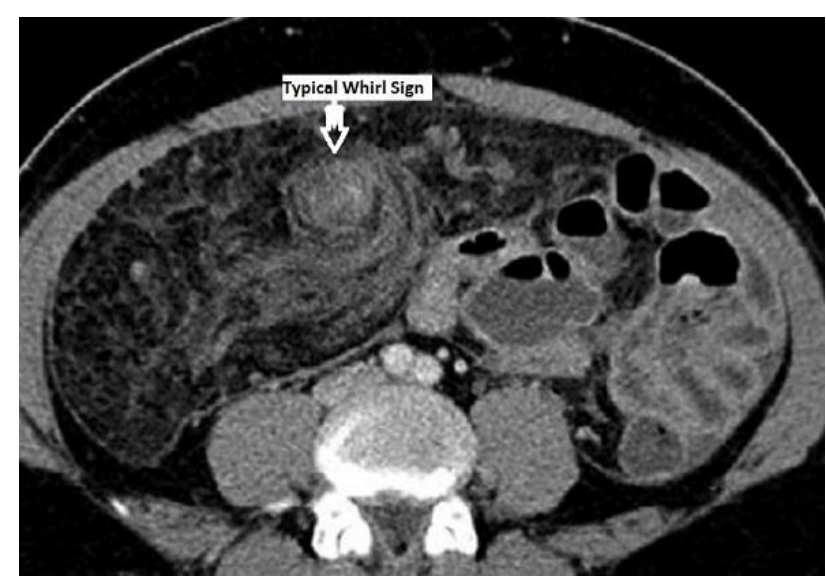

Figure 4: CECT appearance in omental torsion.

\section{TREATMENT}

Surgery is the mainstay of treatment. A diagnostic laparoscopy can help in confirming the diagnosis. ${ }^{6}$ If the mass is smaller in size, laparoscopic resection is a feasible option. However, if the mass is large in size, it is advisable to resect it by formal exploratory laparotomy. Great care needs to be exercised while separating the mass from the colon. ${ }^{7,8}$ The role of conservative treatment has been described. ${ }^{9}$ However, it runs a risk of missing dangerous lesions such as acute appendicitis. ${ }^{10}$

\section{CONCLUSION}

The attending surgeon needs to be aware of this rare condition especially while postulating a differential diagnosis for acute right sided abdominal pain in obese individuals. USG may provide important clues to the diagnosis. CECT is diagnostic. Formal exploratory laparotomy is mainstay of the treatment and permits meticulous and careful dissection of the ischemic mass from the colon.

\section{ACKNOWLEDGEMENTS}

The authors would like to thank Parth K. Vagholkar for his help in typesetting the manuscripts.
Funding: No funding sources

Conflict of interest: None declared

Ethical approval: Not required

\section{REFERENCES}

1. Eitel G. Rare omental torsion. NY Med Rec. 1899;55:715-6.

2. Pinedo-Onofre JA, Guevara-Torres L. Omental torsion: a cause of acute abdomen. Gaceta Medica de Mexico. 2007;143(1):17-20.

3. Itenberg E, Mariadason J, Khersonsky J, Wallack M. Modern management of omental torsion and omental infarction: a surgeon's perspective. J Surg Edu. 2010;67(1):44-7.

4. Schlesinger AE, Dorfman SR, Braverman RM. Sonographic appearance of omental infarction in children. Pediatr Radiol. 1999;29(8):598-601.

5. Maeda T, Mori H, Cyujo M, Kikuchi N, Hori Y, Takaki H. CT and MR findings of torsion of greater omentum: a case report. Abdominal Imaging. 1997;22(1):45-6.

6. Sánchez J, Rosado R, Ramírez D, Medina P, Mezquita S, Gallardo A. Torsion of the greater omentum: treatment by laparoscopy. Surg Laparoscopy, Endoscopy Percutaneous Tech. 2002;12(6):443-5.

7. Adams JT. Primary torsion of the omentum. The Am J Surg. 1973;126(1):102-5.

8. Albuz O, Ersoz N, Kilbas Z, Ozerhan IH, Harlak A, Altinel O, Yigit T. Primary torsion of omentum: a rare cause of acute abdomen. The Am J Emerg Med. 2010;28(1):115.e5-7.

9. Fragoso AC, Pereira JM, Estevão-Costa J. Nonoperative management of omental infarction: a case report in a child. J Pediatr Surg. 2006;41(10):1777-9.

10. Kimber CP, Westmore P, Hutson JM, Kelly JH. Primary omental torsion in children. Journal of Paediatrics and Child Health. 1996;32(1):22-4.

Cite this article as: Vagholkar K, Chougle Q, Agrawal P, Daga D, Vagholkar S. Omental torsion: a rare cause of acute abdomen. Int Surg J 2016:3:1711-3. 